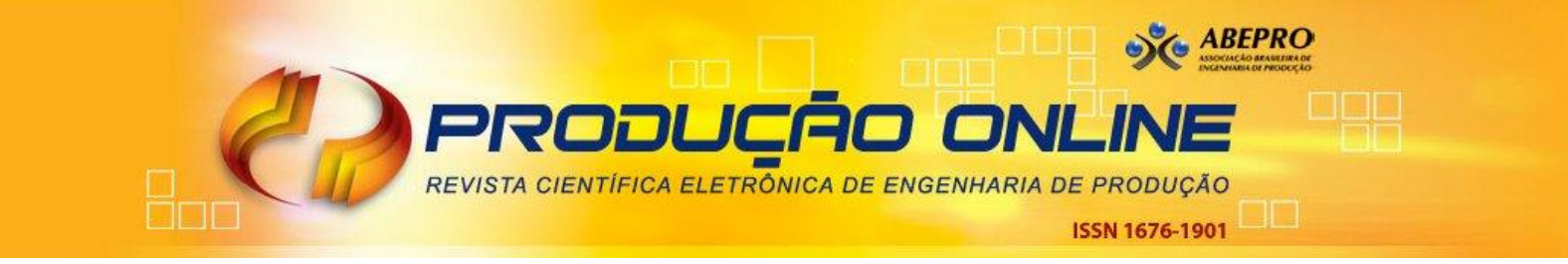

\title{
AVALIAÇÃO ECONÔMICO-FINANCEIRA DE SISTEMAS DE MANEJO DE ÁGUAS RESIDUÁRIAS DE ORIGEM DOMÉSTICA EM EMPREENDIMENTOS HABITACIONAIS
}

\section{ECONOMIC AND FINANCIAL EVALUATION OF WASTE WATER MANAGEMENT SYSTEMS OF DOMESTIC ORIGIN IN HOUSING PROJECTS}

\author{
Maria Caroline Carneiro Silva* E-mail: mcarolinecs@gmail.com \\ Joséte Florencio dos Santos*E-mail: ifs@ufpe.br \\ *Universidade Federal de Pernambuco (UFPE), Recife, PE
}

\begin{abstract}
Resumo: O propósito deste estudo é avaliar a viabilidade econômico-financeira dos sistemas de manejo de águas residuárias de origem doméstica em empreendimentos habitacionais de interesse social. Trata-se de dois sistemas compartimentados anaeróbio/aeróbio/anóxica vertical para remoção de carbono e nitrogênio. A análise econômico-financeira do projeto piloto dos sistemas compartimentados foi composta pelo Valor Presente de Custo, Custo Anual Uniforme Equivalente, Entradas de caixa de Breakeven, Análise de sensibilidade e Simulação de Monte Carlo. O resultado da análise tradicional considerou o melhor resultado as premissas "Com Reuso e Sem Investimento Inicial". De acordo com as entradas de caixa de Breakeven, quanto maior for o custo de capital, maior a entrada de caixa requerida para que o projeto seja viável. Para a análise de sensibilidade, o custo do projeto a valor presente diminui à medida que o custo do capital aumenta, reduzindo, assim, a inviabilidade. No Custo Anual Uniforme Equivalente, nas premissas "sem investimento inicial" e "com investimento inicial" quanto maior o custo de capital, menor e maior o CAUE, respectivamente. Nas simulações de Monte Carlo realizadas, as análises baseadas na interpretação de indicadores tradicionais foram extremamente otimistas, contudo pouco representam a realidade, tanto que a probabilidade de ocorrência é menor que $1 \%$.
\end{abstract}

Palavras-chave: Sistema compartimentado. Avalição econômico-financeira. Método Tradicional. Análise de risco e incerteza. Simulação de Monte Carlo.

Abstract: The purpose of this study is to evaluate the economic and financial viability of domestic wastewater management systems in housing developments of social interest. These are two compartmentalized anaerobic / aerobic / anoxic vertical systems for removal of carbon and nitrogen. The economic-financial analysis of the pilot project of the compartmentalized systems was composed by Cost Present Value, Equivalent Annual Uniform Cost, Breakeven Box Inputs, Sensitivity Analysis and Monte Carlo Simulation. The result of the traditional analysis considered the best result the assumptions "With Reuse and Without Initial Investment". According to Breakeven cash inflows, the higher the cost of capital, the greater the cash inflow required to make the project viable. For the Sensitivity Analysis, the cost of the project to Present Value decreases as the cost of capital increases, thus reducing non-viability. In the Equivalent Uniform Annual Cost, in the assumptions "without initial investment" and "with initial investment" the higher the cost of capital, the lower and higher the CAUE, respectively. In the Monte Carlo Simulations performed, the analyzes based on the interpretation of traditional indicators were extremely optimistic, but they do not represent reality, so that the probability of occurrence is less than $1 \%$.

Keywords: System compartmentalized. Economic and financial review. Traditional method. Analysis of risk and uncertainty. Monte Carlo simulation.

Revista Produção Online. Florianópolis, SC, v.17, n. 2, p. 378-405, 2017. 


\section{INTRODUÇÃO}

O Plano Nacional de Saneamento Básico (PLANSAB) elaborado de acordo com a Lei $11.445 / 07$ do Governo Federal, sob a coordenação do Ministério das Cidades (art. 52), visa viabilizar os investimentos no âmbito governamental, estabelecer diretrizes nacionais e políticas federais para o saneamento básico, a fim de minimizar o déficit de investimento e universalizar o serviço de saneamento, que são de fundamental importância para a saúde pública e para o meio ambiente.

Segundo a Fundação Nacional de Saúde (FUNASA) (2011), estima-se que para cada $R \$ 1,00$ investido em saneamento, $R \$ 4,00$ são economizados no tratamento de doenças oriundas da ausência de esgotamento sanitário. O Sistema Único de Saúde (SUS) calcula que as despesas com o tratamento de doenças relacionadas à falta de higiene cheguem a $\mathrm{R} \$ 300$ milhões por ano.

Com a finalidade de reduzir as perdas humanas e ambientais, o PLANSAB visa ampliar em 93\% a cobertura do saneamento básico das áreas urbanas no período de 20 anos, além de extinguir os esgotos sem tratamento através da implementação de sistemas centralizados e descentralizados de tratamento de efluentes.

Um sistema de tratamento de esgoto centralizado envolve coletores, interceptores e emissários, estações elevatórias, estações de tratamento e disposição de efluentes e lodo. Entretanto, apesar dos benefícios para a saúde e para o meio ambiente que podem ser alcançados em virtude da implantação do saneamento básico, o modelo de sistemas de esgotamento sanitário centralizado em vigor causa impactos ambientais negativos, decorrentes da supressão de cobertura vegetal e das obras como poeira, ruídos, riscos de acidentes, ocorrência de odores fétidos em estações de tratamento de esgotos (ETE's), além dos impactos potenciais relativos à disposição do lodo, que pode contaminar o solo, as águas superficiais e subterrâneas (DELTA SANEAMENTO, 2015).

Já o sistema descentralizado apresenta-se como uma alternativa viável para o cumprimento desta meta porque alia tecnologias de sistemas de tratamento a sistemas de baixo custo de instalação, operação e manutenção. De acordo com Ros e Vrtovsek (1998), Lacalle et al (2001), Garbossa et al (2005) e Chernicharo (2006), a utilização de sistemas combinados anaeróbicos-aeróbio é viável porque requer 
uma área menor para sua implantação, menores custos operacionais e contribuem tanto para a preservação do meio ambiente como para a saúde pública através do controle de helmintoses e doenças entéricas.

Nesse sentido, a Rede Nacional de Tratamento de Esgotos Descentralizados (RENTED) está direcionada ao desenvolvimento de sistemas locais e descentralizados de manejo de águas residuárias de origem doméstica, incluindo aspectos de sustentabilidade e gerenciamento de subprodutos líquidos, sólidos e gasosos. O foco principal da Rede, que é financiada pela FINEP e formado por pesquisadores de 13 universidades (UFSC, UFPE, UFC, UFSM, UEPB, UFMG, UFBA, UNB (FUB), UFPA, UFMS, USP, UFES, UFAL), consiste no desenvolvimento de soluções para tratamento de esgotos de moradias de interesse social, como 0 programa "Minha Casa Minha Vida". A Rede está também possibilitando estudos de avaliação do ciclo de vida, análise de risco microbiológico e químico, além de análises de viabilidade econômica de sistemas descentralizados unifamiliares e multifamiliares (BRASIL e FEESC, 2015).

Como integrante da RENTED, o Laboratório de Saneamento Ambiental (LSA) da Universidade Federal de Pernambuco (UFPE) está desenvolvendo dois tipos de sistemas compartimentados anaeróbio/aeróbio/anóxica vertical para remoção de carbono e nitrogênio: (1) que na fase anóxica recebe o esgoto bruto como doador de elétrons para promover a desnitrificação; (2) que na fase anóxica recebe etanol como doador de elétrons para promover a desnitrificação. Esses sistemas pretendem tratar o esgoto de modo descentralizado e almejam, a partir de uma técnica simples e de fácil instalação, reduzir o impacto ambiental negativo e aliar o baixo custo com um elevado retorno ambiental, social e econômico.

Baseado nisso, o propósito deste estudo será avaliar a viabilidade econômicofinanceira dos sistemas de manejo de águas residuárias de origem doméstica em empreendimentos habitacionais de interesse social, como o programa "Minha Casa Minha Vida", através de métodos tradicionais de avaliação de investimentos e da simulação de Monte Carlo.

Para efeitos do estudo em foco, foram utilizados os métodos do Valor Presente Líquido (VPL), Valor Presente de Custo (VPC) e o Custo Anual Uniforme Equivalente (CAUE). Além disso, foram realizadas as análises de risco e incerteza 
através das entradas de caixa de Breakeven, análise de sensibilidade e simulação de Monte Carlo.

É importante ressaltar que os sistemas compartimentados avaliados por este estudo são equipamentos que não visam o ganho financeiro, nem a obtenção de lucro, visto que não há geração de receita. O objetivo destes sistemas é reduzir os custos de instalação, manutenção e operação dos sistemas de tratamento de esgotos a fim de viabilizar a implementação do saneamento básico em moradias de interesse social.

Portanto, esta pesquisa visa a responder a seguinte pergunta: Qual é o impacto financeiro para implementar um sistema compartimentado anaeróbio/aeróbio/ anóxica vertical de manejo de águas residuárias de origem doméstica em empreendimentos habitacionais de interesse social?

\section{DESENVOLVIMENTO}

\subsection{Tratamento de Esgoto Descentralizado}

Segundo Naphi (2004), o sistema descentralizado é um sistema de esgotos domésticos que são financeiramente mais acessíveis, socialmente responsáveis e ambientalmente benéficos, visto que não há mistura dos resíduos industriais com os domésticos; utiliza tecnologias com menos investimentos em manutenção; reduz os custos, uma vez que não necessita de utilização de canais para o transporte dos resíduos; o efluente tratado está prontamente disponível para reutilização; possibilita a expansão do sistema; facilidade de planejamento e execução, já que os projetos são simples; há possibilidade de empregar diferentes estratégias de gestão financeiramente e ambientalmente eficientes.

Nessa direção, este trabalho tem como objetivo avaliar a viabilidade econômica dos sistemas descentralizados de manejo de águas residuárias através dos:

1. Sistema compartimentado anaeróbio, aeróbio e anóxica para a remoção de carbono e nitrogênio usando como fonte de carbono, na fase anóxica, o esgoto bruto; 
2. Sistema compartimentado anaeróbio, aeróbio e anóxica para a remoção de carbono e nitrogênio usando como fonte de carbono, na fase anóxica, o etanol.

Esses sistemas realizam um tratamento terciário que visa à remoção de carbono, nitrogênio e ovos helmintos por meio de um sistema compartimentado vertical dividido em três compartimentos, conforme Figura 1.

No primeiro compartimento ocorre a fase anaeróbia, isso quer dizer que o tratamento é realizado por bactérias que não necessitam de oxigênio para o crescimento, são capazes de remover a matéria orgânica e promover a amonificação parcial dos compostos nitrogenados. No segundo compartimento acontece a fase aeróbia que, ao contrário da fase anterior, o tratamento é realizado por bactérias que necessitam de oxigênio para o crescimento e são capazes de remover a matéria orgânica remanescente além de promover a nitrificação dos compostos amonificados. No último compartimento ocorre a fase anóxica que visa a desnitrificação através do esgoto bruto (Sistema 1) ou Etanol (Sistema 2) como doador de elétrons. Segundo Santos (2004), o etanol justifica-se por se mostrar mais eficiente como doador de elétrons durante a disnitrificação.

Figura 1 - Sistema compartimentado anaeróbio-aeróbio-anóxica. Fonte: Laboratório de Saneamento Ambiental (2014)

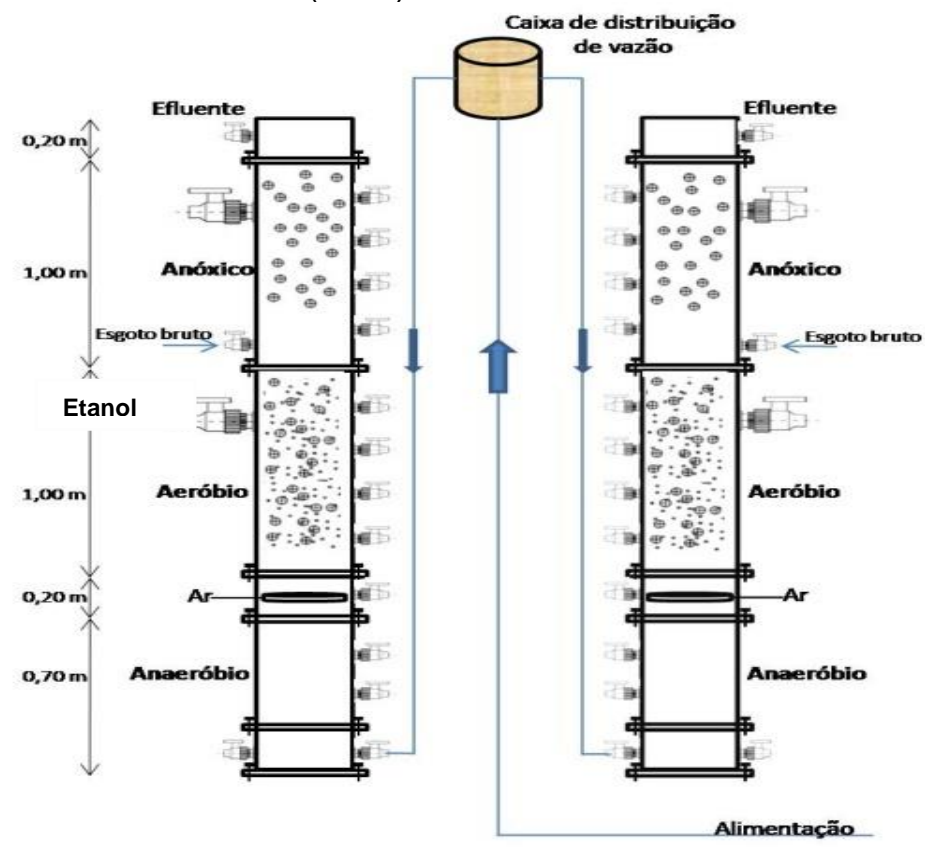

Fonte: Laboratório de Saneamento Ambiental (2014)

Revista Produção Online. Florianópolis, SC, v.17, n. 2, p. 378-405, 2017. 
Os sistemas compartimentados (Figura 1) realizam o tratamento em 10 (dez) horas e têm a capacidade de atender a uma população com 10 habitantes e um volume de $0,39(\mathrm{~m} 3)$ no modelo piloto que está sendo desenvolvido junto à Estação de Tratamento de Esgoto da Mangueira na Região Metropolitana de Recife.

Os sistemas têm como objetivo estabelecer uma tecnologia de tratamento alternativa, compacta e de baixo custo que produza efluente tratado conforme padrão de emissão estabelecido na legislação brasileira, a nível Federal, pela resolução do Conselho Nacional do Meio Ambiente - CONAMA 357/2005 e conforme a demanda da RENTED.

\subsection{Avaliação de investimentos}

Segundo Assaf Neto (1992), a avaliação de investimentos é um estudo que se refere às decisões de aplicações de capital em projetos que garantam retornos por vários períodos consecutivos. De modo que, em determinado período, uma empresa possa ser considerada como um conjunto de projetos de investimento em diferentes fases de execução. Sendo assim, o objetivo financeiro, ao avaliar as alternativas de investimento, passa a ser o de maximizar a contribuição marginal desses recursos de capital a fim de promover o incremento da riqueza.

Segundo Pindyck (1988), grande parte, ou até mesmo a totalidade dos gastos com investimentos em projetos reais, é irreversível. Dessa maneira, a maior dificuldade ao se elaborar a análise de um projeto de investimento é combinar os dados presentes, de modo que, as variações futuras em custos, receitas e horizonte de planejamento, entre outras, sejam consideradas na análise. Com isso, o processo decisório de uma empresa torna-se complexo, visto que as estimativas e cálculos devem refletir as informações disponíveis de maneira ampla e concisa (OLIVEIRA, 2008).

\subsection{Coleta de informações e montagem do fluxo de caixa}

O fluxo de caixa foi construído com os dados primários coletados no Laboratório de Saneamento Ambiental da UFPE, responsável pela construção e operação dos reatores compartimentados anaeróbio/aeróbio/anóxico vertical.

Revista Produção Online. Florianópolis, SC, v.17, n. 2, p. 378-405, 2017. 
Para construir o fluxo de caixa, segundo Correa (2002) e Oliveira (2001), composto pelas entradas e saídas de recursos, expressos em unidades monetárias que ocorrem ao longo do desenvolvimento de um projeto, foram consideradas as seguintes variáveis: investimento inicial e entradas de caixa operacionais composto pelo horizonte de planejamento, receita, custo e taxa de depreciação.

O investimento inicial é ponto de partida para compor um fluxo de caixa, ou seja, é a saída de caixa na data zero. Foram considerados, na base de cálculo do investimento inicial, o custo com matéria-prima para construção do reator ( $R \$$ $3.879,61)$, serviços de instalação $(R \$ 3.600,00)$ e aquisição de equipamentos elétricos e hidráulicos complementares $(R \$ 2.450,76)$, totalizando o investimento inicial em $\mathrm{R} \$ 9.930,37$.

O horizonte de planejamento refere-se à duração do projeto ou a sua vida útil. Para este estudo foi adotado uma vida útil de 20 (vinte) anos conforme convenção da ABNT 15.575/2.013 para este tipo de equipamento, contudo é necessário obedecer a periodicidade e os processos de manutenção segundo a ABNT NBR 5674 e detalhado no manual de uso, operação e manutenção elaborado em atendimento à ABNT NBR 14037.

No caso desta avaliação, consideram-se duas premissas com relação à receita auferida do projeto. Na primeira a receita é nula porque não há o reuso de água, ou seja, a água tratada pelo reator é devolvida para o meio ambiente. $\mathrm{Na}$ segunda, a receita será de $R \$ 154,08$ referente à redução na despesa de água devido à utilização de água de reuso gerada pelos reatores. Para mensurar a receita, foi considerada a tarifa social da Compesa de $R \$ 6,42 /$ mês para até 10.000 Litros/Mês referente ao custo da água tratada e 100\% da tarifa de água referente ao esgotamento sanitário determinada pela resolução da Arpe no 89/2014 publicada no DOE no 25 de 06/02/2014.

O custo com energia elétrica deriva do uso de bomba e compressor que oxigena as bactérias e bombeia o efluente para dentro do sistema compartimentado. O total gasto com energia foi de $R \$ 2.986,20$ e a base de cálculo utilizou o preço da tarifa de energia elétrica da Celpe de acordo com a Resolução Homologatória N0 1723 de 28 de abril de 2014 que determina valor consumo (R\$/kWh) com PIS/COFINS isento de ICMS de $\mathrm{R} \$ 0,3532$ (trinta e cinco centavos) para classe 
residencial convencional de baixa tensão/renda (B1) com consumo acima de 220 kWh.

A manutenção anual da bomba e compressor que impulsiona a entrada do esgoto bruto no reator e que mantém a oxigenação das bactérias na parte aeróbica do tratamento está prevista em $\mathrm{R} \$ 50,00$ anual equivalente ao preço do produto utilizado para evitar ferrugens e ressecamento do equipamento.

Contudo, é necessário o desembolso financeiro de $\mathrm{R} \$ 2.450,76$ referente à substituição de duas bombas, os dois compressores e o filtro de ar a cada 5 anos, conforme Norma de Execução $n^{\circ}$ 06, publicada no Diário Oficial da União de 30 de dezembro de 1993 que determina a depreciação de equipamentos elétricos e hidráulicos em $20 \%$ ao ano.

A depreciação do reator, que é mensurada a partir do investimento inicial (custo de construção e instalação) dividido pela vida útil, totaliza em $R \$ 373,98$. Enquanto que a depreciação dos equipamentos (bomba, compressor e filtro de ar) diminuídos em $20 \%$ ao ano, conforme Norma de Execução $n^{\circ} 06$, publicada no Diário Oficial da União de 30 de dezembro de 1993 que determina a depreciação de equipamentos elétricos e hidráulicos, totaliza em $R$ \$ 490,15.

O primeiro ano do fluxo de caixa foi construído com os valores referentes ao ano de 2014, ano da coleta dos dados, e os anos seguintes foram reajustados anualmente de acordo com a média do índice de inflação IGP-M divulgada pelo Banco Central do Brasil através do Sistema de Expectativas do Mercado em Março de 2015. É importante ressaltar que o IGP-M foi escolhido por ser o índice utilizado para balizar os reajustes das tarifas de energia elétrica e de água. Após a determinação da taxa de reajuste, os fluxos de caixa foram reajustados pelo sistema de expectativa do IGP-M até o ano de 2018 (ano 5) e os demais anos são reajustados com a taxa de 2018 (taxa constante), conforme Tabela 1.

Tabela 1 - Reajuste Anual do Fluxo de Caixa de acordo com o IGP-M (Taxa Constante)

\begin{tabular}{ccc}
\hline Ano & Taxa de Reajuste do Fluxo de Caixa (ano base 2014) \\
\hline & $5,79 \%$ & $\begin{array}{c}\text { Sistema de } \\
\text { Expectativa do } \\
\text { Mercado }\end{array}$ \\
2015 & $5,38 \%$ & \\
2016 & $5,20 \%$ & Taxa Constante \\
2018 & $5,11 \%$ & \\
2019 a 2033 & $5,11 \%$ & \\
\hline Fonte: Elaboração Própria & & \\
Revista Produção Online. Florianópolis, SC, v.17, n. 2, p. 378-405, 2017.
\end{tabular}


Em seguida, as entradas de caixa foram contabilizadas usando um formato de demonstração de resultados. Contudo, é importante ressaltar que por se tratar de uma avaliação de investimento de um equipamento, não há abatimento do imposto de renda.

Após o lançamento das variáveis, foram encontrados valores negativos caracterizando saídas de caixa operacionais. E, conforme dito anteriormente, os anos 5, 10 e 15 apresentam valores superiores devido à substituição dos equipamentos (bombas, compressores e filtro de ar).

Após a primeira e a segunda etapa, compostas pela coleta de informações e montagem do fluxo de caixa, serão apresentados os métodos utilizados na avaliação de investimento para determinar a viabilidade econômico-financeira do reator.

\subsection{Método da análise dos dados}

Após o levantamento de dados, foi procedida a análise do investimento através de técnicas e modelos matemáticos onde se verifica a alocação do capital investido e o custo anual dos sistemas.

Os critérios de tomada de decisão baseados em análise de viabilidade econômica serão Valor Presente de Custo (VPC), Custo Anual Uniforme Equivalente (CAUE), entradas de caixa de Breakeven, análise de sensibilidade e simulação de Monte Carlo. Para cálculo destas taxas foi empregado o software Excel, do pacote Microsoft Office 2013.

\subsubsection{Valor Presente de Custo}

Neste estudo, as entradas de caixa foram negativas, mesmo nos cenários em que foram consideradas receitas oriundas do reuso de água tratada pelo sistema, as saídas de caixa foram maiores do que as entradas de caixa. Dessa forma a análise foi realizada pela ótica do Valor Presente de Custo.

Esse método permite identificar a alternativa de menor custo para obter determinado resultado e é utilizado quando se compara projetos com benefícios, e de difícil valorização. Ademais, serve para comparação de dois ou mais projetos 
mutuamente excludentes, cujos benefícios brutos são idênticos e muito difíceis de medir (BOTTEON, 2009).

No caso deste estudo, esse indicador pode ser utilizado para escolha do sistema que permitirá alcançar a finalidade de garantir o saneamento básico num empreendimento habitacional. Como não há dúvidas quanto aos benefícios obtidos pelo tratamento de esgoto, todos os habitantes do país devem ter acesso. É exatamente por isto que se busca a alternativa de menor custo para alcance deste objetivo.

$$
\begin{aligned}
& \text { Equação } 1 \text { - Valor Presente de Custo } \\
& \qquad P P C=\sum_{J=0}^{n} C_{j}(1+i)^{-j}
\end{aligned}
$$

Onde:

Cj: valor dos custos.

i: taxa de juros de $5 \%$ e de $12 \%$.

j: período em que as receitas ou os custos ocorrem.

$\mathrm{n}$ : número de períodos ou duração do projeto que é de 20 anos.

\subsubsection{Custo Anual Uniforme Equivalente (CAUE)}

O Custo Anual Uniforme Equivalente (CAUE), ou Valor Presente Líquido Anualizado (VPLA), permite a comparação entre dois ou mais investimentos apresentando o mais baixo custo anual, corrigido ao fator tempo. Além disso, determina o período ideal para a substituição do equipamento, partindo do pressuposto de que, quanto mais longa for a vida de um ativo depreciável, mais baixo será o Custo Médio Anual do Capital, visto que o desembolso será distribuído sobre um período mais longo de tempo; isso, todavia, será contrabalançado por custos operacionais crescentes; e, assim sendo, a vida útil econômica se encerra no período (ano) em que o custo total, devidamente ajustado ao tempo, atingir um mínimo (DE ROCCHI, 1987). 
Equação 2 - Custo Anual Uniforme Equivalente

$$
\text { CAUE }=\frac{V P C \mathrm{t}}{\left[\frac{i_{p}{ }^{3}\left(1+i_{f}\right)^{t}}{\left(1+i_{p}\right)^{t}-1}\right]}
$$

Onde:

VPL: Valor Presente Líquido.

ir: taxa de desconto de $5 \%$ e $12 \%$.

t: período de tempo que é de 20 anos referente a vida útil do projeto.

\subsubsection{Entradas de Caixa de Breakeven}

As entradas de caixa de Breakeven consideram um nível mínimo de entrada de caixa necessário para que os projetos sejam aceitáveis. Para este estudo, foram calculadas 41 entradas de caixa de Breakeven a fim de construir diversos cenários para auxiliar na tomada de decisão e na análise de viabilidade econômico-financeira do projeto. As entradas de caixa de Breakeven foram simuladas a partir da variação do custo de capital de $12 \%$ em dez pontos percentuais para mais e para menos com intervalo de 0,50 pontos percentuais.

Equação 3 - Entradas de Caixa de Breakeven

$$
\mathrm{VPL}=[\mathrm{FC} \times(\mathrm{FVPAr}, \mathrm{n})]-\mathrm{FC} 0>\$ 0
$$

Onde:

VPL: Valor Presente Líquido

FVPA: Fator de Valor Presente de Anuidade

r: Custo de capital

$\mathrm{n}$ : Número de anos

FC: Entrada de caixa anual

FC0: Investimento inicial 


\subsubsection{Análise de Sensibilidade}

Segundo Abreu (2008), a análise de sensibilidade é composta pela análise do impacto das variações nos valores de uma determinada variável sobre os índices financeiros determinísticos do projeto, definindo a quais parâmetros tais índices são mais sensíveis. Segundo Bruni, Fama e Siqueira (1998), qualquer componente do fluxo de caixa pode ser uma variável sensibilizada, entretanto, custo de capital ou a taxa de crescimento é a variável mais sensibilizada do fluxo de caixa futuro.

Baseadas nisso, as alterações do custo de capital são realizadas em diversos pontos percentuais, em seguida é calculado um VPC para cada percentual, a fim de indicar qual a sensibilidade do VPC a estas mudanças, e como isto impactará na viabilidade do projeto.

O intervalo dos custos de capital foi determinado a partir da série histórica da Selic, através da distribuição de probabilidade do Crystal Ball. Para um intervalo de confiança de $95 \%$, a taxa mínima encontrada foi de $7 \%$ a.a. e a máxima $22 \%$ a.a., com intervalo de 0,5 pontos percentuais.

\subsubsection{Simulação de Monte Carlo}

A análise tradicional pressupõe o cálculo dos indicadores financeiros e possibilita associar valores para os cenários discretos a fim de verificar qual resultado ocorrerá em cada situação. Enquanto que, a Simulação de Monte Carlo (SMC) permite uma abordagem de risco que possibilita alcançar um modelo mais consistente, com capacidade de capturar o caráter estocástico da base de dados estudada.

A simulação de Monte Carlo foi realizada com o uso do software de análise de risco Crystal Ball, em conjunto com a planilha eletrônica Microsoft Excel. A simulação foi realizada a partir de 50.000 iterações para fornecer o resultado final, que no caso deste estudo, foi o VPC e o CAUE.

Em síntese, este trabalho trata da viabilidade econômico-financeira de um projeto piloto de sistemas compartimentados que visam tratar o esgoto de forma descentralizada a partir de dados reais de receita e custos, descritos na seção 2.3, com aplicação do "input" gerando os "outputs" probabilísticos.

Revista Produção Online. Florianópolis, SC, v.17, n. 2, p. 378-405, 2017. 
Para isso, o primeiro passo consiste na definição da variável aleatória, aquelas que podem sofrer modificações e influenciar diretamente no resultado da análise do investimento. As variáveis consideradas para essa simulação foram: tarifa de água, tarifa de energia, tarifa do etanol e valores dos equipamentos elétricos que serão substituídos a cada 5 anos.

O segundo passo consiste na determinação do "input" utilizado que foi o IGPM por ser o indexador da tarifa de energia elétrica e da tarifa de água, que são as variáveis mais significativas presentes no fluxo de caixa do projeto. Para fins do estudo, foram utilizados os valores médios do IGP-M, que refletem o valor esperado do índice de inflação divulgada pelo Banco Central do Brasil através do Sistema de Expectativas do Mercado divulgado em março de 2015 para os anos de 2015, 2016, 2017 e 2018. Apesar de o ano de 2019 ter sido divulgado pelo Sistema, ele foi retirado da amostra por não conter todos os valores médios diários. Sendo assim, foram considerados os valores de 2018 como constante até 2033, término da vida útil dos sistemas analisados.

O terceiro passo para realização da simulação, é a identificação das distribuições de probabilidades das variáveis aleatórias definidas no modelo. Neste caso, o comportamento apresentado foi Extremo Mínimo de Distribuição, conforme descrito na Figura 2, que apresenta os valores mais prováveis de ocorrência do IGPM, de acordo com a Moda.

Figura 2 - Extremo Mínimo Distribuição

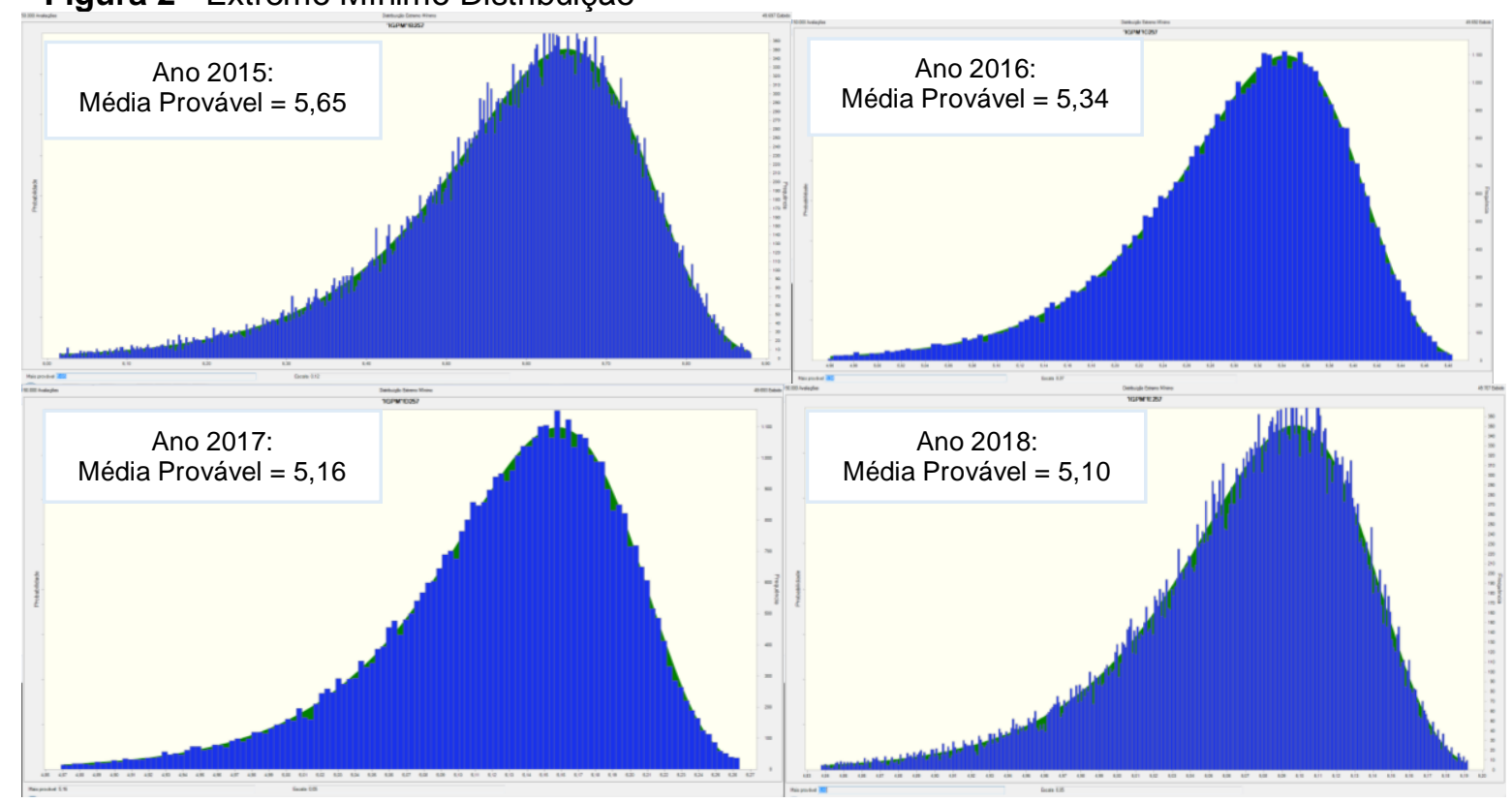

Fonte: Elaboração Própria

Revista Produção Online. Florianópolis, SC, v.17, n. 2, p. 378-405, 2017. 
$\mathrm{Na}$ simulação é importante ressaltar os valores do percentil que define o menor valor de um conjunto de " $n$ " valores de uma variável, ordenados de forma crescente (BITTENCOURT, 2005). Neste caso, foi considerado um percentil de $10 \%$, isso significa que esse valor é maior que os primeiros $10 \%$ dos outros valores ordenados de forma crescente e inferior aos $90 \%$ dos valores restantes, conforme Tabela 2.

Tabela 2- Percentil do IGP-M por ano

\begin{tabular}{|c|c|c|c|c|}
\hline Percentil & \multicolumn{4}{|c|}{ Extremo Mínimo Distribuição } \\
\hline & 2015 & 2016 & 2017 & 2018 \\
\hline $0 \%$ & -Infinito & -Infinito & -Infinito & -Infinito \\
\hline $10 \%$ & 5,38 & 5,18 & 5,04 & 4,99 \\
\hline $20 \%$ & 5,47 & 5,23 & 5,08 & 5,02 \\
\hline $30 \%$ & 5,53 & 5,27 & 5,10 & 5,05 \\
\hline $40 \%$ & 5,57 & 5,29 & 5,12 & 5,06 \\
\hline $50 \%$ & 5,61 & 5,32 & 5,14 & 5,08 \\
\hline $60 \%$ & 5,64 & 5,34 & 5,15 & 5,09 \\
\hline $70 \%$ & 5,67 & 5,36 & 5,17 & 5,11 \\
\hline $80 \%$ & 5,71 & 5,38 & 5,18 & 5,12 \\
\hline $90 \%$ & 5,75 & 5,40 & 5,20 & 5,14 \\
\hline $100 \%$ & +Infinito & +Infinito & +Infinito & +Infinito \\
\hline
\end{tabular}

Fonte: Elaboração Própria

Por fim, foram definidos os "outputs" do projeto que serão o valor mínimo, o valor máximo, o valor esperado e o desvio padrão do Valor Presente de Custo e do Custo Anual Uniforme Equivalente que corresponde ao valor médio dos VPC's e CAUE's calculados, associado ao caráter aleatório do IGP-M.

\subsection{Resultados}

\subsubsection{Análise Tradicional da Viabilidade Econômico-financeira}

Exposto o projeto de investimento, inicia-se a fase referente à sua avaliação econômico-financeira. Este tipo de avaliação, em geral, almeja quantificar o resultado do investimento. Nesta subseção será apresentado o cálculo determinístico do VPC e CAUE. Estes métodos consideram as variáveis de caixa e o investimento em valores absolutos, não sendo considerada a incerteza presente. Os valores utilizados para elaboração dos cálculos foram apresentados na Seção 2.3. A avaliação foi realizada com base em quatro (4) premissas:

Revista Produção Online. Florianópolis, SC, v.17, n. 2, p. 378-405, 2017. 
1. Sem Reuso: a água tratada pelo sistema é devolvida ao meio ambiente;

2. Com Reuso: a água tratada pelo sistema é utilizada na área externa dos empreendimentos habitacionais, minimizando o custo com a água tratada e esgotamento sanitário;

3. Com Investimento Inicial: considera a construção e instalação dos sistemas em empreendimento habitacional já construído;

4. Sem Investimento Inicial: considera que o custo de construção e instalação dos sistemas está implícito na construção do empreendimento habitacional.

As premissas foram combinadas entre si e formaram quatro (4) cenários para cada Sistema:

1. Com Investimento Inicial (II) e Sem reuso (SR);

2. Com Investimento Inicial (II) e Com reuso (SR);

3. Sem Investimento Inicial (II) e Sem reuso (SR);

4. Sem Investimento Inicial (II) e Com reuso (SR).

Em seguida, foram calculados o VPC e CAUE para cada premissa, a um custo de capital de $12 \%$. A taxa de $12 \%$ foi escolhida por ser uma por determinação da RENTED e por refletir o custo de capital de uma pessoa jurídica. Neste caso, uma empresa privada ou pública seria a responsável pela construção, instalação, manutenção e operação do projeto.

Vale ressaltar que, o VPC e o CAUE permitem a operacionalização a partir de informações referentes aos custos dos sistemas, já que se trata da avaliação de um equipamento que não gera receita financeira e não visa a obtenção do lucro.

Com um custo de capital de $12 \%$, o melhor resultado encontrado para o Sistema 1 foi um VPC de $-\mathrm{R} \$ 34.061,50$ e um CAUE - $R \$ 4.560,11$. No caso, do Sistema 2, o melhor resultado encontrado foi um VPC de -R $\$ 35.925,59$ e um CAUE -R $\$ 4.809,67$. Os resultados obtidos pelo VPC (Tabela 4) demonstram que a diferença financeira entre o Sistema 1 e 2 é fixa em $R \$ 1.864,09$. 
Tabela 4 - Resultado do VPC e CAUE do Sistema 1 e 2 com fluxos de caixa reajustados pelo sistema de expectativa do IGP-M até o ano de 2018 (ano 5) e a uma taxa constante até 2033 (ano 20) - custo de capital de $12 \%$

Reator com Esgoto Bruto (1)

\begin{tabular}{|c|c|c|c|c|c|}
\hline \multicolumn{2}{|c|}{ Custo de Capital $=12 \%$} & VPC (anual) & VPC (anual/hab) & CAUE (anual) & CAUE (anual/hab) \\
\hline \multirow{2}{*}{ Com II } & Sem Reuso & $-\mathrm{R} \$ 45.614,06$ & $-\mathrm{R} \$ 4.561,41$ & $-\mathrm{R} \$ 6.072,05$ & $-\mathrm{R} \$ 607,20$ \\
\hline & Com reuso & $-R \$ 43.991,87$ & $-R \$ 4.399,19$ & $-R \$ 5.889,58$ & $-R \$ 588,96$ \\
\hline \multirow{2}{*}{ Sem II } & Sem Reuso & $-\mathrm{R} \$ 35.683,69$ & $-\mathrm{R} \$ 3.568,37$ & $-\mathrm{R} \$ 4.777,29$ & $-\mathrm{R} \$ 477,73$ \\
\hline & Com reuso & $-\mathrm{R} \$ 34.061,50$ & $-R \$ 3.406,15$ & $-R \$ 4.560,11$ & $-R \$ 456,01$ \\
\hline \multicolumn{6}{|c|}{ Reator com Etanol (2) } \\
\hline & & VPC (anual) & VPC (anual/hab) & CAUE (anual) & CAUE (anual/hab) \\
\hline \multirow{2}{*}{ Com II } & Sem Reuso & $-\mathrm{R} \$ 47.478,15$ & $-\mathrm{R} \$ 4.747,81$ & $-\mathrm{R} \$ 6.356,32$ & $-\mathrm{R} \$ 635,63$ \\
\hline & Com reuso & $-R \$ 45.855,96$ & $-\mathrm{R} \$ 4.585,60$ & $-\mathrm{R} \$ 6.139,14$ & $-\mathrm{R} \$ 613,91$ \\
\hline \multirow{2}{*}{ Sem II } & Sem Reuso & $-\mathrm{R} \$ 37.547,78$ & $-\mathrm{R} \$ 3.754,78$ & $-\mathrm{R} \$ 5.026,85$ & $-\mathrm{R} \$ 502,69$ \\
\hline & Com reuso & $-R \$ 35.925,59$ & $-R \$ 3.592,56$ & $-R \$ 4.809,67$ & $-R \$ 480,97$ \\
\hline
\end{tabular}

Fonte: Elaboração Própria

Os resultados obtidos pelo VPC (Tabela 3 ) demonstram que a diferença financeira entre o Sistema 1 e 2 é fixa em $R \$ 1.864,09$, independente da premissa. Isso ocorre porque o Sistema 1 recebe o esgoto bruto como doador de elétron para as bactérias desnitrificantes na fase anóxica e o custo dessa operação é zero porque ela utiliza o próprio esgoto como fonte. Enquanto que o Sistema 2 recebe o etanol como doador de elétron para as bactérias desnitrificantes na fase anóxica, o que gera um custo extra com o etanol.

Os resultados expostos neste estudo referem-se à fase experimental do projeto que atende a 10 habitantes, sendo assim o custo anual uniforme equivalente por habitante, no melhor cenário, seria de $\mathrm{R} \$ 456,01$. Enquanto que, o custo anual por habitante beneficiado pela Tarifa Social da Compesa é de $\mathrm{R} \$ 154,08$ (tarifa de água mais esgotamento sanitário), isso significa um custo incremental por habitante de $\mathrm{R} \$ 301$, para implementar um Sistema Compartimentado nos empreendimentos habitacionais.

Segundo a Fundação Nacional de Saúde (FUNASA) (2011), estima-se que para cada $R \$ 1,00$ investido em saneamento, $R \$ 4,00$ são economizados no tratamento das doenças oriundas da ausência de esgotamento sanitário. Nesse caso, haveria uma redução de $\mathrm{R} \$ 1.824,04$ no Sistema Único de Saúde por habitante.

Ademais, observa-se que, tanto no Sistema 1 como no Sistema 2, os cenários compostos pela hipótese "sem investimento inicial" apresentaram um VPC menor Revista Produção Online. Florianópolis, SC, v.17, n. 2, p. 378-405, 2017. 
que os cenários compostos pela hipótese "com investimento inicial". A diferença entre esses cenários foi de $\mathrm{R} \$ 9.930,37$, que corresponde exatamente ao valor do Investimento Inicial de cada Sistema.

Neste sentido, como era de se esperar, o melhor resultado considera as premissas "Com Reuso e Sem Investimento Inicial". Isso quer dizer que, quanto maior for a tarifa de água, mais viável torna-se o projeto, ou seja, a tarifa de água apresenta uma relação negativa com o VPC. É importante ressaltar que a tarifa de água é analisada do ponto de vista da receita porque significa o que o empreendimento habitacional deixa de gastar com tarifas de água e esgoto cobradas das companhias estaduais de saneamento básico ao utilizar água de reuso oriunda do sistema. Enquanto que a premissa sem investimento inicial considera que o custo de construção e instalação do sistema esteja implícito no custo de construção do empreendimento.

\subsubsection{Entradas de Caixa de Breakeven}

A entrada de caixa de Breakeven considera um nível mínimo de entrada de caixa necessário para que os sistemas sejam aceitáveis, ou seja, valor mínimo necessário para obter o retorno do investimento.

Neste sentido, este estudo realizou uma simulação utilizando a técnica em questão com o intuito de investigar a sensibilidade das entradas de caixa em função da variação do custo de capital obtendo-se, para um investimento inicial de $R \$$ 9.930,37 e uma vida útil de 20 anos, uma relação positiva entre as entradas de caixa e o custo de capital. Dessa forma, quanto maior for o custo de capital, maior a entrada de caixa requerida para que o projeto seja considerado viável (Gráfico 1).

A análise de sensibilidade das entradas de caixa de Breakeven demonstra que até a taxa de $7,50 \%$ o projeto exigirá entradas mínimas de caixa menor que $\mathrm{R} \$$ $1.000,00$ ao ano. Ademais, a análise demonstra que é necessário ultrapassar o custo de capital de $19,50 \%$ para que o projeto demande entradas mínimas de caixa maior que $\mathrm{R} \$ 2.000,00$.

De acordo com a FUNASA (2011) para cada $R \$ 1,00$ investido em saneamento, $\mathrm{R} \$ 4,00$ são economizados no tratamento das doenças oriundas da ausência de esgotamento sanitário. Dessa forma, para entradas mínimas requeridas 
de $R \$ 1.329,47$, ao custo de capital de $12 \%$ a.a., seriam economizados $R \$ 5.317,86$ no Sistema Único de Saúde.

Figura 3 - Entradas de Caixa de Breakeven

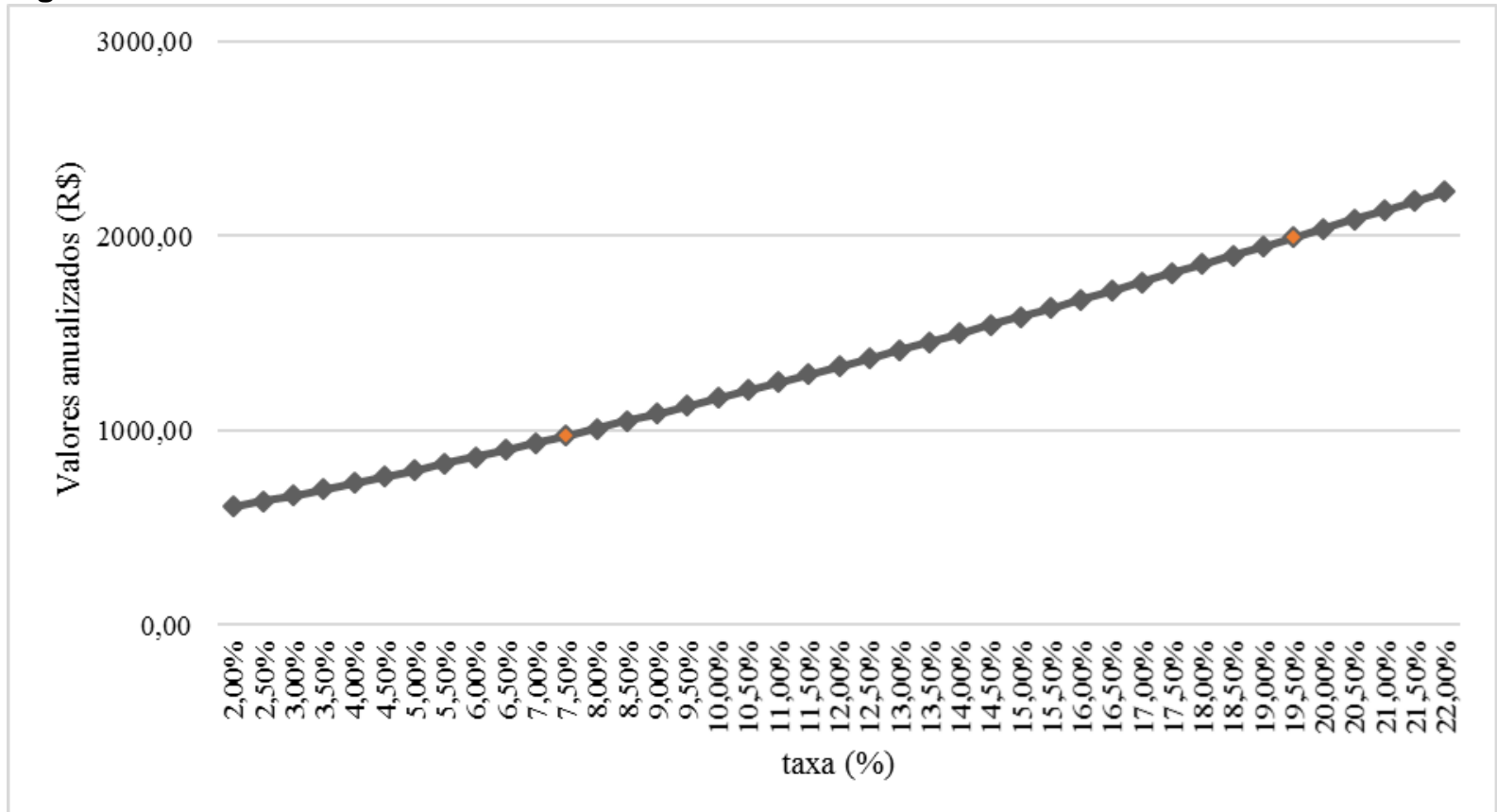

Fonte: Elaboração Própria

\subsubsection{Análise de Sensibilidade}

O objetivo da análise de sensibilidade é determinar os parâmetros mais importantes do projeto e aqueles capazes de influenciar fortemente os resultados dos indicadores financeiros tradicionais. O parâmetro financeiro considerado para a análise de sensibilidade dos indicadores tradicionais foi o custo de capital, por ser a variável mais sensibilizadora.

A Figura 4, abaixo, apresenta graficamente o impacto da variação do custo de capital nos resultados do Valor Presente de Custo (VPC) dos sistemas compartimentados. O resultado indica que todas as variações no custo de capital (\%) apresentaram uma relação negativa com relação ao VPC. Isso quer dizer que o custo do projeto a valor presente diminui à medida que o custo do capital aumenta, tornando o projeto menos inviável. 
Figura 4 - Sensibilidade do VPC ao Custo de Capital

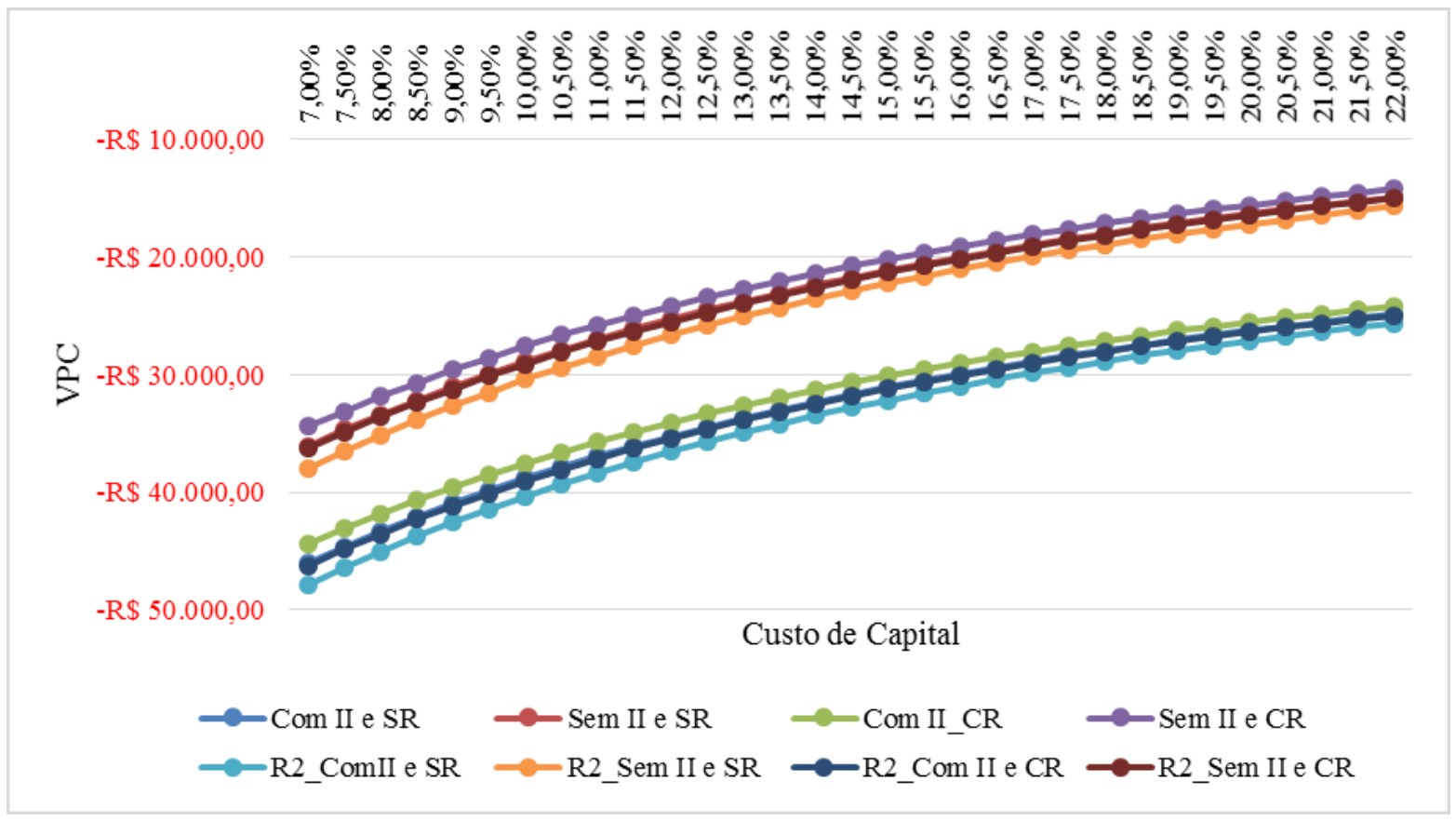

Fonte: Elaboração Própria

Contudo, observa-se que, nas premissas com investimento inicial, o aumento do custo de capital faz com que o VPC tenda ao valor do investimento inicial. Enquanto que, nas premissas sem investimento, o aumento do custo de capital conduz o VPC a zero, que é o limite, ou seja, o aumento do custo de capital, por si só, não transformará os resultados de negativos para positivos.

Assim como foi apresentado na seção 2.5.1, os valores obtidos pelos sistemas apresentaram o mesmo comportamento, o Sistema 2 apresenta valores maiores que o Sistema 1, e as premissas que consideraram o investimento inicial no seu cálculo tiveram um custo mais elevado.

A análise de sensibilidade do impacto da variação do custo de capital nos resultados do Custo Anual Uniforme Equivalente (CAUE), Figura 5, apresenta dois comportamentos distintos. No caso da premissa "sem investimento inicial" os resultados apresentam uma relação negativa, ou seja, quanto maior o custo de capital, menor o CAUE. Enquanto que a premissa "com investimento inicial" apresenta uma relação positiva, quanto maior o custo de capital, maior o CAUE.

Ademais, observa-se que, nas premissas com investimento inicial, o aumento do custo de capital faz com que o CAUE tenda a valores infinitos. Enquanto que, nas premissas sem investimento, o aumento do custo de capital conduz o CAUE a Revista Produção Online. Florianópolis, SC, v.17, n. 2, p. 378-405, 2017. 
valores do fluxo de caixa que é o limite, a partir disso, pode-se continuar aumentando o custo de capital, que o CAUE permanecerá constante.

Figura 5 - Sensibilidade do CAUE ao Custo de Capital

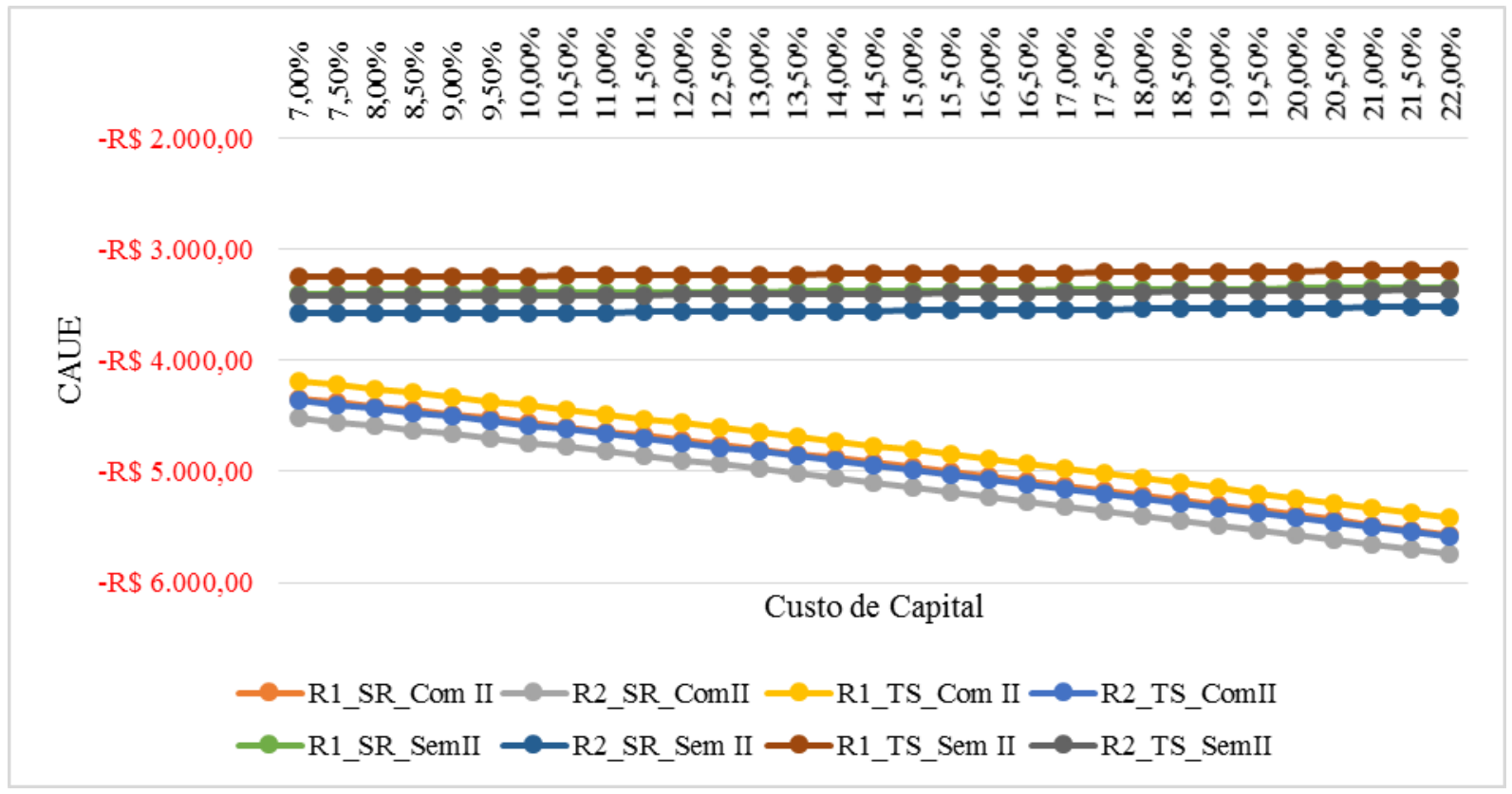

Fonte: Elaboração Própria

\subsubsection{Simulação de Monte Carlo}

O principal objetivo da análise de risco deste projeto foi o de verificar o impacto do caráter aleatório do IGP-M no fluxo de caixa do projeto mediante a aplicação do método da Simulação de Monte Carlo. Para isso, foram geradas 50.000 séries sintéticas considerando os diversos percentuais do IGP-M para o cálculo dos valores esperados dos indicadores financeiros.

Em síntese, o método é uma forma de avaliação interativa de um modelo tradicional, por meio de números aleatórios que estão ligados às entradas e saídas de caixa usadas no cálculo do VPC, de modo que as alterações no fluxo de caixa se assumam como cenários aleatórios. É importante ressaltar que os resultados aleatórios desempenham as distribuições de probabilidade pré-definidas baseandose em dados obtidos da análise de projeções futuras. A definição das distribuições de probabilidades é realizada sobre fatores que compõem o cálculo do VPC, onde o ato de produzir aleatoriamente esses fatores permite ao VPC assumir diversos valores.

Revista Produção Online. Florianópolis, SC, v.17, n. 2, p. 378-405, 2017. 
Por isso, a Simulação Monte Carlo tem sido reconhecida como uma grande ferramenta para tomadores de decisão, por permitir que o risco seja considerado na análise de investimento e no processo de projeção de fluxo de caixa.

Assim como foi realizado na análise tradicional, seção 2.5.1, a avaliação foi realizada com base em quatro premissas: (1) Com Investimento Inicial (II) e Sem Reuso (SR); (2) Com Investimento Inicial (II) e Com Reuso (SR); (3) Sem Investimento Inicial (II) e Sem Reuso (SR); (4) Sem Investimento Inicial (II) e Com Reuso (SR).

Para cada premissa a análise feita pelo Modelo de Monte Carlo realizou distribuições probabilísticas do VPC e do CAUE do Sistema 1 e 2, para o fluxo de caixa de 20 anos. Todavia, enquanto a Simulação de Monte Carlo simulava 50.000 diferentes situações para um único fluxo de caixa utilizando as mesmas premissas, o Método Tradicional apresentava apenas uma situação para cada fluxo de caixa.

Outrossim, de acordo com o coeficiente de variação, as 50.000 séries geradas foram suficientes para originar resultados consistentes e próximos da realidade porque apresentaram valores menores ou iguais a $5 \%$. Dessa maneira, os coeficientes de variação do VPC e CAUE dos Sistemas 1 e 2 para as premissas que consideram o investimento inicial foram de $-0,0026$ e para as premissas que não consideram o investimento inicial foram -0,0033.

Ademais, as simulações apresentaram uma distribuição Lognormal, que foi aceita com 1\% de significância nos testes Qui-quadrado, Kolmogorov-Smirnov (K-S) e Anderson-Darling (A-D). O Qui-Quadrado é um teste de hipótese não paramétrico, que não depende dos parâmetros populacionais (média e variância) e se destina a comparar as possíveis divergências entre as frequências observadas e esperadas para certo evento. Já o teste Kolmogorov-Smirnov (K-S) é utilizado para determinar se duas distribuições de probabilidade subjacentes diferem uma da outra ou diferem da distribuição em hipótese, em ambos os casos, com base em amostras finitas. Contudo, o teste Kolmogorov-Smirnov é mais sensível em pontos próximos da mediana da distribuição, do que nas caudas. Enquanto que o teste Anderson-Darling (A-D) é um teste que providencia igual sensibilidade nas caudas.

A curva Lognormal, por sua vez, aparece naturalmente como produto de várias variáveis independentes, assim como uma distribuição normal aparece quando são somadas várias variáveis independentes. Muito embora, os dados Revista Produção Online. Florianópolis, SC, v.17, n. 2, p. 378-405, 2017. 
resultantes de uma distribuição Lognormal possam ser analisados segundo uma distribuição Normal se tratado com o logaritmo dos dados ao invés dos valores originais.

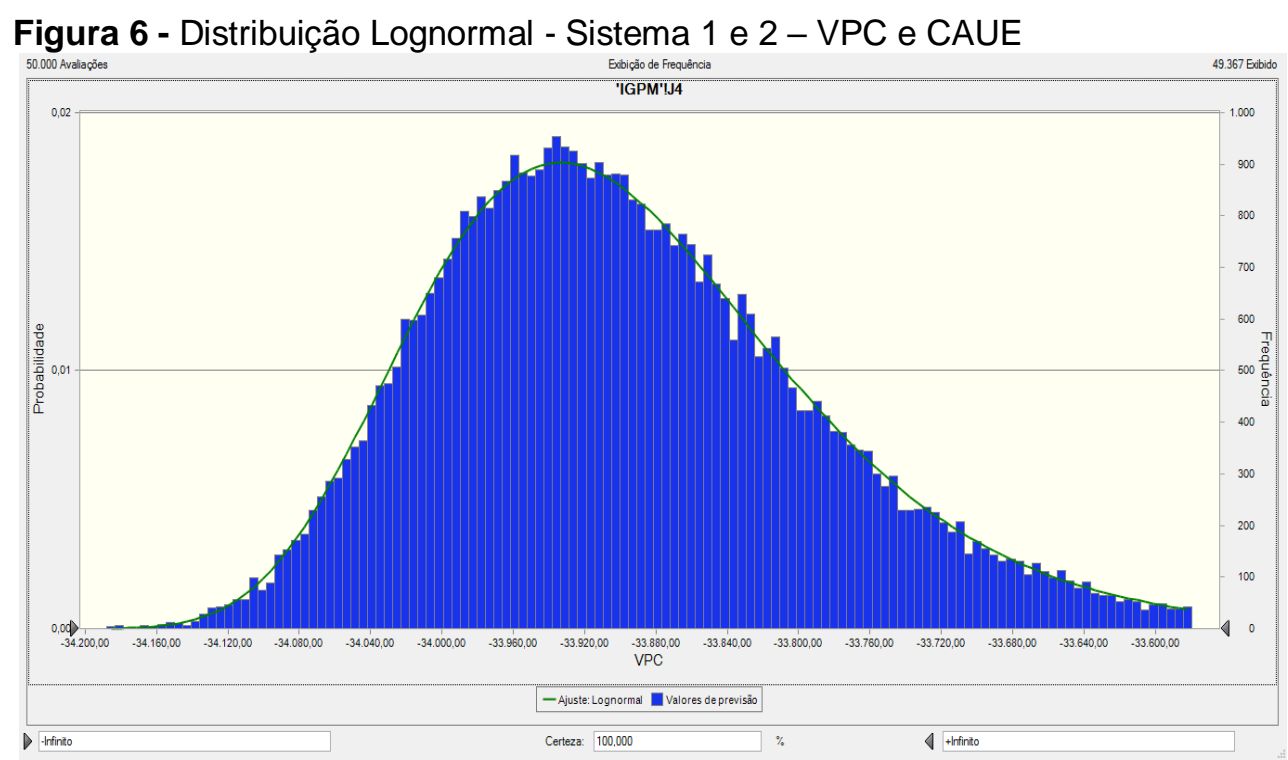

Fonte: Elaboração Própria

Além disso, foram observados os valores mínimos e máximos, a média e o desvio padrão das simulações. O desvio-padrão é uma medida de dispersão estatística que mostra o quanto de variação ou "dispersão" existe em relação à média (ou valor esperado), de modo que um desvio padrão baixo indica que os dados tendem a estar próximos da média, enquanto que um desvio padrão alto indica que os dados estão espalhados por uma gama de valores.

Neste sentido, a primeira simulação realizada do Sistema 1 para a premissa "Com Investimento Inicial e Sem Reuso" apresenta o valor mínimo do VPC de -R\$ 45.760,95, o valor máximo de $-\mathrm{R} \$ 44.608,93$, a média de $-\mathrm{R} \$ 45.440,19$ e o desvio padrão de 117,76. Enquanto que, o resultado da simulação do CAUE apresenta o valor mínimo de $-\mathrm{R} \$ 6.126,42$, o valor máximo de $-\mathrm{R} \$ 5.972,19$, a média de $-\mathrm{R} \$$ $6.083,48$ e o desvio padrão de 15,77.

A segunda simulação considera a premissa "Com Investimento Inicial e Com Reuso" e apresenta o valor mínimo do VPC de -R $\$ 44.143,38$, o valor máximo de $\mathrm{R} \$ 43.066,88$, a média de $-\mathrm{R} \$ 43.825,75$ e o desvio padrão de 112,48 . Enquanto que o resultado da simulação do CAUE apresenta o valor mínimo de $R \$ 5.909,86$, o valor máximo de $-\mathrm{R} \$ 5.765,74$, a média de $-\mathrm{R} \$ 5.867,34$ e o desvio padrão de 15,06 .

Revista Produção Online. Florianópolis, SC, v.17, n. 2, p. 378-405, 2017. 
A terceira simulação realizada considera a premissa "Sem Investimento Inicial e Sem Reuso" e apresenta o valor mínimo do VPC de $-R \$ 35.822,45$, o valor máximo de $-\mathrm{R} \$ 34.497,64$, a média de $-\mathrm{R} \$ 35.509,71$ e o desvio padrão de 118,27. Enquanto que o resultado da simulação do CAUE apresenta o valor mínimo de $\mathrm{R} \$$ $4.795,87$, o valor máximo de $-R \$ 4.618,50$, a média de $-R \$ 4.754,00$ e o desvio padrão de 15,83.

A quarta simulação realizada considera a premissa "Sem investimento inicial e Com Reuso" e apresenta o valor mínimo do VPC -R $\$ 34.187,87$, o valor máximo de $-R \$ 33.045,09$, a média de $-R \$ 33.894,84$ e o desvio padrão de 112,55 . Enquanto que o resultado da simulação do CAUE apresenta o valor mínimo de -R $\$ 4.577,03$, o valor máximo de $-\mathrm{R} \$ 4.424,04$, a média de $-\mathrm{R} \$ 4.537,80$ e o desvio padrão de 15,07 .

A Tabela 5 contempla os valores dos VPC's e CAUE's que corresponde ao decil, que é qualquer um dos nove valores que dividem em dez partes iguais os dados ordenados de uma variável, de modo que cada parte representa 1/10 da amostra. Dessa forma, o primeiro decil de 10\%, por exemplo, corresponde ao VPC de $R \$-45.576,70$, significando dizer que este valor é o ponto de corte para $10 \%$ dos dados mais baixos. $5^{\circ}$ decil é o ponto de corte para $50 \%$ dos dados e significa a mediana. Por fim o 9 decil, que é o limite para $90 \%$ dos dados mais baixos.

Tabela 5 - Decil do Sistema 1

\begin{tabular}{|c|c|c|c|c|c|c|}
\hline \multirow{2}{*}{$\begin{array}{l}\text { Sistema } 1 \text { - Esgoto } \\
\text { Bruto }\end{array}$} & \multicolumn{3}{|c|}{ Valores Previstos de VPC (-R $\$)$} & \multicolumn{3}{|c|}{$\begin{array}{l}\text { Valores Previstos do CAUE } \\
(-R \$)\end{array}$} \\
\hline & $10 \%$ & $50 \%$ & $90 \%$ & $10 \%$ & $50 \%$ & $90 \%$ \\
\hline $\begin{array}{l}\text { Com Investimento } \\
\text { inicial e Sem } \\
\text { Reuso }\end{array}$ & $45.576,79$ & $45.454,92$ & $45.286,60$ & $6.101,76$ & $6.085,45$ & $6.062,92$ \\
\hline $\begin{array}{l}\text { Com Investimento } \\
\text { inicial e Com } \\
\text { Reuso }\end{array}$ & $43.955,54$ & $43.839,44$ & $43.679,07$ & $5.884,71$ & $5.869,17$ & $5.847,70$ \\
\hline $\begin{array}{l}\text { Sem Investimento } \\
\text { inicial e Sem } \\
\text { Reuso }\end{array}$ & $35.645,56$ & $35.524,62$ & $35.355,77$ & $4.772,18$ & $4.755,99$ & $4.733,39$ \\
\hline $\begin{array}{l}\text { Sem Investimento } \\
\text { inicial e Com } \\
\text { Reuso }\end{array}$ & $34.025,09$ & $33.908,79$ & $33.747,59$ & $4.555,24$ & $4.539,67$ & $4.518,09$ \\
\hline
\end{tabular}

Fonte: Elaboração própria

A primeira simulação realizada para o Sistema 2 considera a premissa "Com Investimento Inicial e Sem Reuso" e apresenta o valor mínimo do VPC de -R\$ 
47.643,70, o valor máximo de $-\mathrm{R} \$ 46.473,89$, a média de $-\mathrm{R} \$ 47.294,49$ e o desvio padrão de 124,71. Enquanto que o resultado da simulação do CAUE apresenta o valor mínimo de $-\mathrm{R} \$ 6.378,48$, o valor máximo de $-\mathrm{R} \$ 6.221,87$, a média de $-\mathrm{R} \$$ $6.331,73$ e o desvio padrão de 16,70.

A segunda simulação considera a premissa "Com Investimento Inicial e Com Reuso" e apresenta o valor mínimo do VPC de -R\$46.005,88, o valor máximo de $\mathrm{R} \$ 44.703,64$, a média de $-\mathrm{R} \$ 45.679,46$ e o desvio padrão de 119,55 . Enquanto que o resultado da simulação do CAUE apresenta o valor mínimo de -R\$6.159,21, o valor máximo de $-\mathrm{R} \$ 5.984,87$, a média de $-\mathrm{R} \$ 6.115,51$ e o desvio padrão de 16,01 .

A terceira simulação considera a premissa "Sem Investimento Inicial e Sem Reuso" e apresenta o valor mínimo do VPC de -R\$37.703,15, o valor máximo de $R \$ 36.511,53$, a média de $-\mathrm{R} \$ 37.364,65$ e o desvio padrão de 123,92 . Enquanto que o resultado da simulação do CAUE apresenta o valor mínimo de -R $\$ 5.047,65$, o valor máximo de $-\mathrm{R} \$ 4.888,12$, a média de $-\mathrm{R} \$ 5.002,33$ e o desvio padrão de 16,59 .

A quarta simulação realizada considera a premissa "Sem Investimento Inicial e Com Reuso" e apresenta o valor mínimo do VPC de $-\mathrm{R} \$ 36.090,66$, o valor máximo de $-\mathrm{R} \$ 34.825,23$, a média de $-\mathrm{R} \$ 35.750,67$ e o desvio padrão de 118,78 . Enquanto que o resultado da simulação do CAUE apresenta o valor mínimo de -R\$ $4.831,77$, o valor máximo de $-\mathrm{R} \$ 4.662,36$, a média de $-\mathrm{R} \$ 4.786,26$ e o desvio padrão de 15,90 .

Tabela 6 - Decil do Sistema 2

\begin{tabular}{|c|c|c|c|c|c|c|}
\hline \multirow{2}{*}{ Sistema 2 - Etanol } & \multicolumn{3}{|c|}{ Valores Previstos de VPC (-R\$) } & \multicolumn{3}{|c|}{ Valores Previstos do CAUE (-R\$) } \\
\hline & $10 \%$ & $50 \%$ & $90 \%$ & $10 \%$ & $50 \%$ & $90 \%$ \\
\hline $\begin{array}{l}\text { Com Investimento } \\
\text { inicial e Sem } \\
\text { Reuso }\end{array}$ & $47.439,26$ & $47.309,52$ & $47.131,72$ & $6.351,11$ & $6.333,74$ & $6.309,94$ \\
\hline $\begin{array}{l}\text { Com Investimento } \\
\text { inicial e Com } \\
\text { Reuso }\end{array}$ & $45.817,59$ & $45.694,04$ & $45.523,09$ & $6.134,00$ & $6.117,46$ & $6.094,58$ \\
\hline $\begin{array}{l}\text { Sem Investimento } \\
\text { inicial e Sem } \\
\text { Reuso }\end{array}$ & $30.806,68$ & $30.706,41$ & $30.568,30$ & $4.124,36$ & $4.110,94$ & $4.092,45$ \\
\hline $\begin{array}{l}\text { Sem Investimento } \\
\text { inicial e Com } \\
\text { Reuso }\end{array}$ & $35.888,54$ & $35.764,70$ & $35.594,95$ & $4.804,71$ & $4.788,13$ & $4.765,41$ \\
\hline
\end{tabular}

Fonte: Elaboração própria 
De acordo com os resultados encontrados nas simulações de Monte Carlo realizadas, as análises baseadas na interpretação de indicadores tradicionais foram extremamente otimistas, contudo pouco representam a realidade, tanto que a probabilidade de ocorrência é menor que $1 \%$.

Neste caso, a simulação de Monte Carlo apresentou-se como uma alternativa bastante razoável, por ser mais ajustada à realidade e capaz de reduzir a incerteza no processo de decisão. Além disso, as análises propiciaram maior confiabilidade e buscaram realizar as inferências para analisar o grau de risco do projeto a fim de oferecer informações simples para a tomada de decisões estratégicas com maior precisão.

\section{CONSIDERAÇÕES FINAIS}

O grande diferencial deste trabalho foi tratar o estudo de viabilidade a partir de dados reais relacionados à implementação e operação de um sistema compartimentado anaeróbico - aeróbio - anóxica vertical, que visa tratar o esgoto de forma descentralizada.

Também merece destaque o Método de Simulação de Monte Carlo (SMC) para a geração das 50.000 séries sintéticas, aplicadas no cálculo dos indicadores financeiros probabilísticos, fornecendo resultados mais consistentes e confiáveis, pois é incorporado o caráter aleatório ao fluxo de caixa. Com isso, foi possível aferir até que ponto as oscilações do IGP-M irão influir nos fluxos de caixa futuros do projeto, o denominado "risco" e que as análises baseadas na interpretação de indicadores tradicionais foram extremamente otimistas, contudo pouco representam a realidade, tanto que a probabilidade de ocorrência é menor que $1 \%$.

Diante de tudo o que foi exposto, espera-se que este trabalho possa fornecer condições para a tomada de decisão e que também fomente novos estudos de viabilidade sob o prisma econômico-financeiro, principalmente no âmbito da RENTED, a partir dos dados de construção e implementação de outros sistemas.

Com esse propósito, seguem abaixo algumas recomendações para trabalhos futuros:

- Uso da teoria de opções reais;

- Utilizar outros indexadores como o IPCA e IPC;

Revista Produção Online. Florianópolis, SC, v.17, n. 2, p. 378-405, 2017. 
- Aplicação de diferentes valores de tarifas de energia e de água.

\section{REFERÊNCIAS}

ABREU, V. B. de. Análise da viabilidade econômico-financeira da energia eólica diante do novo contexto do setor elétrico. 2008.96 f. Dissertação (Mestrado em Economia). Universidade Federal de Pernambuco, Recife, 2008.

ANP. Agência Nacional do Petróleo, Gás Natural e Biocombustíveis. Sistema de levantamento de preços. Disponível em: <

http://www.anp.gov.br/preco/prc/Resumo_Por_Estado_Municipio.asp>. Acesso em: 19 jan. 2015.

ASSAF NETO, A. Os métodos quantitativos de análise de investimentos. Caderno de Estudo, n. 06, FIPECAFI: São Paulo, p.79, 1992

Plano Nacional de Saneamento Básico é aprovado com previsão de investimento de $\mathbf{R} \mathbf{\$ 5 0 8 , 5}$ bi até $\mathbf{2 0 3 0}$. Disponível em: <http://www2.planalto.gov.br/excluirhistorico-nao-sera-migrado/plano-nacional-de-saneamento-basico-e-aprovado-comprevisao-de-investimento-de-r-508-5-bi-ate-2030. > Acesso em: 09 set. 2014.

Lei 11.445/2007. Disponível em: < http://www.planalto.gov.br/ccivil_03/_ato20072010/2007/lei/l11445.htm > Acesso em: 13 dez. 2014.

Resolução CONAMA № 357/2005. Disponível em:

<http://www.mma.gov.br/port/conama/legiabre.cfm?codlegi=459> Acesso em: 05 jan. 2015.

Portal da Transparência: Rede Nacional De Tratamento De Esgotos

Descentralizados (RENTED). Disponível em:

$<$ http://www.portaltransparencia.gov.br/convenios/DetalhaConvenio.asp?CodConvenio=6722

$01 \&$ TipoConsulta $=2 \& U F=$ ce $\&$ CodMunicipio $=1389 \&$ Municipio $=$ fortaleza $\&$ CodOrgao $=\& O r g a 0=$ \&Pagina $=\&$ Periodo=1 $>$ Acesso em: 11 fev. 2015.

ABNT - NBR 9648 de 1986. Disponível em: <http://pt.notices-pdf.com/nbr-96481986-pdf.html\#a0> Acesso em: 14 de julho de 2015

BITTENCOURT, R.M. Análise de investimento de uma usina termelétrica: uma abordagem determinística e probabilística. 2005.137f. Dissertação ( Mestrado Profissional em Economia). Universidade Federal de Pernambuco, Recife, 2005

BRUNI, A. L.; FAMÁ, R.; SIQUEIRA, J.O.. Análise do risco na avaliação de projetos de investimento: uma aplicação do método de Monte Carlo. Caderno de Pesquisa em Administração, v.1, n. 6,1998.

CELPE. Estrutura tarifária da Celpe. Disponível em:

http://servicos.celpe.com.br/residencial-rural/Pages/Alta\%20Tens\%C3\%A3o/tarifas-grupoa.aspx . Acesso em: 19 jan. 2015

CHERNICHARO, C.A.L. Post-treatment options for the anaerobic treatment of domestic wastewater. Rev. Environmental Science and Biotechnology, v. 5, p.73-92, 2006. https://doi.org/10.1007/s11157-005-5683-5

Revista Produção Online. Florianópolis, SC, v.17, n. 2, p. 378-405, 2017. 
COMPESA. Estrutura tarifária da Compesa. Disponível em:

https://lojavirtual.compesa.com.br:8443/gsan/exibirConsultarEstruturaTarifariaPortalAction.d o. Acesso em: 19 jan. 2015

CORREA, E. L. A viabilidade econômica do gás natural. Dissertação (Mestrado).

Programa de Pós-graduação em Engenharia de Produção. UFSC. Florianópolis. 2002.

DELTA SANEAMENTO. Saneamento Ambiental através de coleta e tratamento de esgotos. Disponível em: <http://www.deltasaneamento.com.br/noticia/31/saneamentoambiental-atraves-de-coleta-e-tratamento-de-esgotos\#.VOXt9_nF_kU>. Acesso em: 19 fev. 2015.

FEESC. Fundação de Ensino e Engenharia de Santa Catarina. Tratamento do esgoto sanitário. Disponível em: <http://www.feesc.org.br/site/?pg=projeto-tratamento-de-esgotosanitario.> Acesso em: 11 fev. 2015

FUNASA.O desafio de universalizar o saneamento rural. n. 10, dez. 2011. Disponível em: http://www.funasa.gov.br/site/wp-content/files_mf/blt_san_rural.pdf. Acesso em:19 jan. 2015

GARBOSSA, L. H. P. et al. Development and Evaluation of a Radial Anaerobic/Aerobic Reactor Treating Organic Matter and Nitrogen in Sewage. Brazilian Journal of Chemical Engineering, v. 22, p. 511-519, 2005. https://doi.org/10.1590/S0104-66322005000400003

LACALLE, M.L et al. Combined Anaerobic/Aerobic (UASB $p$ UBAF) System for Organic Matter and Nitrogen Removal from a High Strength Industrial Wastewater. Water Science and Technology, v.44, p.255-262, 2001.

LEAL, L. R.; DE OLIVEIRA, M. J. F.. Simulação aplicada ao gerenciamento de projetos: uma revisão. Revista Produção Online, v. 11, n. 2, p. 503-525, 2011.

https://doi.org/10.14488/1676-1901.v11i2.737

MINISTÉRIO DO MEIO AMBIENTE. Governança ambiental. Disponível em:

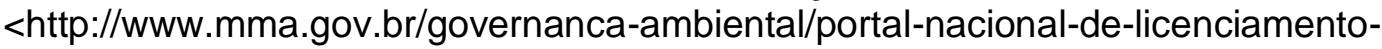
ambiental/licenciamento-ambiental/atualidades-empreendimentos/item/8325>. Acesso em: 20 nov. 2013.

NAPHI, I.. A framework for the decentralised management of wastewater in Zimbabwe. Physics and Chemistry of the Earth, n. 29, p. 1265-1273, 2004.

OLIVEIRA, M. H. F. A avaliação econômico-financeira de investimentos sob condição de incerteza: uma comparação entre o método de Monte Carlo e o VPL Fuzzy. 2008. 231 f. Dissertação (Mestrado em Engenharia de Produção). Universidade de São Paulo, São Carlos, 2008.

PINDYCK, R. S. Irreversible investment, capacity choice, and the value of the fi $\mathrm{rm}$. American Economic Review, v. 78, n. 5, p. 969-985, 1988.

PORTAL BRASIL. Índice geral de preços do mercado - IGP-M. Disponível em: <http://www.portalbrasil.net/igpm.htm>. Acesso em: 28 fev. 2015.

RITTER, F. et al. Utilização do método monte carlo para avaliação econômica de policultivos de jundiás, carpas e tilápias-do-nilo como uma alternativa de modelo de cultivo de peixes para pequenas propriedades. Revista Produção Online, v. 14, n. 4, p. 1292-1315, 2014. https://doi.org/10.14488/1676-1901.v14i4.1590

Revista Produção Online. Florianópolis, SC, v.17, n. 2, p. 378-405, 2017. 
ROS, M. J.; VRTOVSEK, B. Wastewater Treatment and Nutrient Removal in the Combined Reactor. Water Science and Technology, v. 38, p.87-95, 1998.

https://doi.org/10.1016/S0273-1223(98)00393-X

SANTOS, S. G. et al. Comparative research on the use of methanol, ethanol and methane as electron donors for denitrification. In: Anaerobic digestion. Environmental Engineering Science , v. 21, n.3, p. 313-320, 2004. https://doi.org/10.1089/109287504323066950

TARIFA DA CELPE. Disponível em: <file://C:/Users/Maria/Downloads/CELPE\%2020Tabela_Tarifas_Reh_1723_2014\%20(2014-08)-Convencional-Site-BT\%20(1).pdf> Acesso em: 17 dez. 2014

TAXA DE DEPRECIAÇÃO. Disponível em:

<http://www.tj.pr.gov.br/depat/dcp/depreciacao.htm.> Acesso em:17 dez. 2014

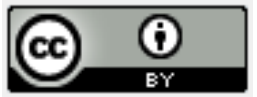

Artigo recebido em 02/08/2015 e aceito para publicação em 06/04/2017

DOI: http://dx.doi.org/10.14488/1676-1901.v17i2.2118 